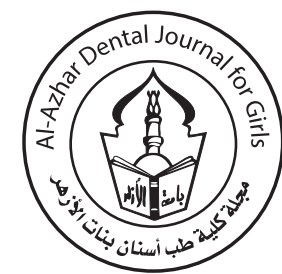

\title{
Impact of Different Movement Kinematics on the Deformation of TF Adaptive Files
}

\author{
Sabah M. Sobhy ${ }^{1}$, Mervat I. Fawzy ${ }^{2}$, Hagar A. Bastawy ${ }^{3}$
}

Codex : 23/1904

azhardentj@azhar.edu.eg

http://adjg.journals.ekb.eg

DOI: $10.21608 /$ adjg.2019.5993.1041

\section{KEYWORDS}

Adaptive motion, Deformation,

Dental operating Microscope

(DOM), Movement Kinematics,

TF Adaptive Files.

\begin{abstract}
Purpose: This study was designed to evaluate the effect of different movement kinematics on the deformation of TF Adaptive files using Dental Operating Microscope (DOM) and Scanning Electron Microscope (SEM). Materials and Methods: One hundred and eighty extracted human mandibular molars were selected with curved mesiobuccal canal $\left(15^{\circ}-35^{\circ}\right)$. Thirty new sets of TF Adaptive files were divided into 3 groups according to the movement kinematics used (10 instruments each). Group I: 60 samples were instrumented with $10 \mathrm{TF}$ Adaptive files in adaptive motion with TF Adaptive program Elements motor. Group II: 60 samples were instrumented with 10 TF Adaptive files in reciprocating motion with built-in reciprocating EndoEst motor mini, where the angle of reciprocation was set at $160^{\circ} \mathrm{CCW}$ and $41^{\circ} \mathrm{CW}$. Group III: 60 samples were instrumented with10 TF Adaptive files in continuous rotation motion at 500rpm and torque $2 \mathrm{~N} / \mathrm{cm}$. Instruments were examined under DOM before usage and after each use for evaluation of deformation or fracture. Selected instruments from each group were evaluated using SEM. Results: there was no statistical significant difference among adaptive motion, reciprocating and continuous rotation motion in the mean deformation scores and percentage. The highest deformation scores and percentage was recorded in TF Adaptive instruments used with continuous rotation motion, however, there was no statistical significant difference. Conclusion: The innovated adaptive motion did not result in lower deformation of TF Adaptive files. Reciprocating motion produced less deformation in TF Adaptive files than did adaptive motion or continuous rotation motion, after preparing six root canals.
\end{abstract}

- Paper extracted from Master thesis titled "Impact of Different Movement Kinematics on the Deformation of TF Adaptive Files".

1. Demonstrator of Endodontics, Endodontic Department, Faculty of Dental Medicine for Girls, Al-Azhar University. Email: sabamorad@yahoo.com

2. Professor of Endodontics, Endodontic Department, Faculty of Dental Medicine for Girls, Al -Azhar University.

3. Associate Professor of Endodontics, Endodontic Department, Faculty of Dental Medicine for Girls, Al -Azhar University. 


\section{INTRODUCTION}

Successful endodontic treatment can be achieved by proper chemo-mechanical preparation eliminating all pulp tissue and microorganisms ${ }^{(1,2)}$. Traditionally, endodontic instruments were manufactured from carbon steel or stainless steel. Authors have found that nickel titanium (NiTi) instruments had greater flexibility and resistance to fracture than similar sized stainless steel instruments ${ }^{(3,4)}$. Despite the increased flexibility the greatest problem of niti files is the unexpected fracture of the instrument ${ }^{(5,6)}$. Metal fatigue increases in curved canals, where the instrument experiences increased tension and compression cycles which increase the possibility of fracture ${ }^{(7)}$. Torsional fatigue is another causative factor that may affect fracture of endodontic instruments.

Possible strategies to enhance fatigue resistance of the instrument include an improvement in the manufacturing process or the use of new alloys that provide superior mechanical properties. Recently, a completely different manufacturing process has been developed to create the twisted file (TF) which was manufactured with a twisting method in combination with heat treatment to improve fatigue resistance ${ }^{(8)}$.

Movement kinematic is an important factor affecting lifespan of NiTi instrument because it determines stress distribution, which instruments accumulate during time. In continuous rotation, file separation has been explained by increased cyclic and torsional fatigue ${ }^{(9)}$.

Several studies have shown that reciprocation is associated with an extended life span of the instrument when compared to conventional rotation. This reveals that reciprocation is a safe alternative to continuous rotation ${ }^{(10-12)}$. It has been reported that decreasing the reciprocation range of the instruments results in increased cyclic fatigue resistance ${ }^{(13,14)}$. Despite the advantages of reciprocation movement, it has disadvantage which seems to increase extrusion of debris beyond the apex and postoperative pain ${ }^{(15,16)}$.

The adaptive motion was introduced combining the advantages of both rotation and reciprocation.
When there is no stress on the file, the motion can be described as rotation. The motion changes into reciprocation when the file is stressed inside the canal ${ }^{(17)}$. Reciprocating motion helps to prevent instruments screwing into the root canal. Screw effect increases stresses on the file thereby increasing the risk of file separation ${ }^{(18)}$.

The study evaluating the fracture resistance of TF Adaptive files under continuous rotation and adaptive motion using a specially manufactured dynamic cyclic fatigue testing device has shown that the adaptive motion had high resistance to fracture when compared to continuous rotation ${ }^{(19)}$. However, there is a limited data available about the incidence of defects in TF Adaptive instruments after repeated clinical use using different movement kinematics. Therefore, the aim of the present study was conducted to evaluate the effect of different movement kinematics on the deformation of TF Adaptive files using Dental Operating Microscope (DOM) and Scanning Electron Microscope (SEM).

\section{MATERIALS AND METHODS}

\section{Samples selection and preparation:}

One hundred and eighty extracted human mandibular molars were selected with mature apices without resorption or cracks, mesial roots having 2 separate mesial canals and apical foramina, an average length of 12 to $14 \mathrm{~mm}$ and the mesiobuccal canal curvature ranged between $15^{\circ}-35^{\circ}$ with radius $<40 \mathrm{~mm}$.

\section{CBCT imaging:}

The samples were placed in plastic dental arches that used as a holder to ensure samples stability during scanning. CBCT scan was acquired using i-CAT imaging system. The mesiobuccal canal was traced to determine the angle and radius of root canal curvature. The angle of curvature was determined by the Schneider's technique and the radius of curvature was measured by the Estrela's method ${ }^{(20,21)}$. 


\section{Instruments' grouping:}

Thirty new sets of TF Adaptive files (Sybron Endo, Orange, CA, USA) were examined before usage using DOM at X25 magnification; the instrument that had any sign of deformation was discarded.

The instruments were divided into 3 groups (I, II and III) according to the movement kinematics used (10 instruments each):

Group I: 60 samples were instrumented with 10 TFA in adaptive motion.

Group II: 60 samples were instrumented with 10 TFA in reciprocating motion.

Group III: 60 samples were instrumented with 10 TFA in continuous rotation motion.

Each instrument was used to prepare six root canals

\section{Root canal instrumentation:}

The meisobuccal root canals were checked for apical patency with \# $10 \mathrm{~K}$-file until it was just visible from the apex and then $1 \mathrm{~mm}$ was subtracted from this length to establish the working length. In all groups, after performing glide path with \#15 Kfile, the root canals were instrumented with TFAdaptive files (SM1) (\# 20, 0.04), followed by TFA files (SM2) (\# 25, 0.06) to the full working length as following; the TF Adaptive file was inserted passively in the canal till reaching the full working length through multiple insertions and the apical movement was incremental and passive.

\section{Group I: (Adaptive motion)}

Sixty root canals were prepared with $10 \mathrm{TF}$ Adaptive files used with TF Adaptive program Elements motor (Sybron Endo, Orange, CA, USA). The feature of this motor is that it changes the kinematics from an interrupted complete rotating movement $\left(600^{\circ} \mathrm{CW}\right.$ horizontal rotational motion and $0^{\circ}$ $\mathrm{CCW})$ to a partial reciprocation $\left(370^{\circ}\right.$ in the cutting verse $\mathrm{CW}$ and $50^{\circ}$ in the noncutting verse $\mathrm{CCW}$ ) depending on the torsional stresses building up on the shaft of the file ${ }^{(22)}$.

\section{Group II: (Reciprocating motion)}

Sixty root canals were prepared with $10 \mathrm{TF}$ Adaptive instruments used in reciprocating motion with built-in reciprocating EndoEst motor mini (Geosoft Dent., Russia), where the angle of reciprocation was set at $160^{\circ} \mathrm{CCW}$ and $41^{\circ} \mathrm{CW}{ }^{(23)}$.

\section{Group III: (Continuous rotation motion)}

Sixty root canals were prepared with $10 \mathrm{TF}$ Adaptive instruments used in continuous rotation motion with EndoEst motor mini (Geosoft Dent., Russia) at 500rpm and torque $2 \mathrm{~N} / \mathrm{cm}$. After each instrument use, irrigation with $2 \mathrm{ml}$ of freshly prepared $2.6 \%$ sodium hypochlorite $(\mathrm{NaOCl})$ solution dispensed through a 31-gauge Navi-Tip flexible irrigation needle, where the needle was inserted as deep as possible into the root canal without binding and EDTA gel was used as a lubricating agent. Each instrument was cleaned with a piece of gauze and alcohol after each use.

\section{Instruments' evaluation:}

\section{a. Using Dental Operating Microscope (DOM):}

TF Adaptive instrument (SM2) was examined using DOM at X25 magnification after each use for evaluation of deformation or fracture which was done according to the scoring criteria by Caballero $^{(24)}$ :

Score1: No Fracture, no plastic deformation, no cracks, no craters, no disruption of the cutting edges or blunt edges along the examined shaft.

Score 2: Plastic deformation, cracks, craters, disruption of the cutting edges or blunt edges of one spiral along the examined shaft.

Score 3: Plastic deformation, cracks, craters, disruption of the cutting edges or blunt edges of two spirals along the examined shaft. 
Score 4: Plastic deformation, cracks, craters, disruption of the cutting edges or blunt edges of more than two spirals along the examined shaft.

Score 5: Fractured instrument.

\section{b. Using Scanning Electron Microscope (SEM):}

Three selected TF Adaptive instrument (SM2) from each group (after $3^{\text {rd }}$ use, after $4^{\text {th }}$ use and after $6^{\text {th }}$ use) were examined under SEM to evaluate the presence of microscopic superficial defects such as microcracks, large crater and disruption of the cutting edges ${ }^{(24)}$.

\section{STATISTICAL ANALYSIS}

Numerical data were explored for normality by checking the distribution of data and using tests of normality (Kolmogorov-Smirnov and Shapiro-Wilk tests). Data were presented as mean and standard deviation (SD). For non-parametric data, KruskalWallis test was used to compare between groups. Friedman's test was used to compare between numbers of uses within each group.

Qualitative data (Number of deformed files) were presented as frequencies (n) and percentages $(\%)$. Chi-square $\left(\mathrm{X}^{2}\right)$ test was used for comparison between the groups. The significance level was set at $\mathrm{P} \leq 0.05$. Statistical analysis was performed with IBM SPSS Statistics Version 20 for Windows.

\section{RESULTS}

I. Dental operating microscope (DOM) results:

I.1 Comparison of deformation scores among the tested groups after each use: (Fig. 1)

\section{First, second and third uses:}

There was no statistical significant difference in the mean deformation scores among the tested groups after each use $(\mathrm{P}>0.05)$.

\section{Fourth use:}

The results showed that, TF Adaptive instruments used with reciprocating motion had lower deformation scores than TF Adaptive instruments used with either adaptive motion or continuous rotation motion. However there was no statistical significant difference among the tested groups in the mean deformation scores $(\mathrm{P}>0.05)$.

\section{Fifth and sixth uses:}

The lowest mean deformation scores was recorded in TFA instruments used with reciprocating motion followed by TF Adaptive instruments used with adaptive motion. The highest mean deformation scores was recorded in TF Adaptive instruments used with continuous rotation motion. However, there was no statistical significant difference among the tested groups in the mean deformation scores $(\mathrm{P}>0.05)$.

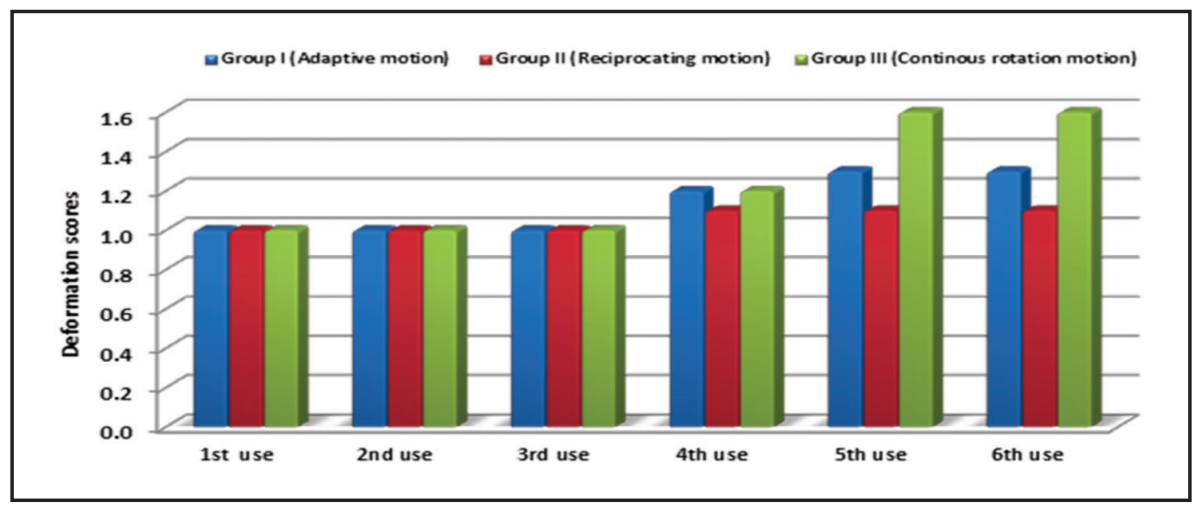

Figure (1): A bar chart comparing the mean deformation scores among the tested groups after each use. 


\section{I.2 Comparison of deformation scores within each tested group after each use: (Table 1)}

\section{Group I (Adaptive motion):}

The mean deformation scores after the first three uses denoting no deformation, then the value is slightly higher after the $4^{\text {th }}$ use followed by $5^{\text {th }}$ and $6^{\text {th }}$ uses and there was no statistical significant difference among the different uses $(\mathrm{P}>0.05)$.

\section{Group II (Reciprocating motion):}

The mean deformation scores after the first three uses denoting no deformation, then the value is slightly higher after the $4^{\text {th }}, 5^{\text {th }}$ and $6^{\text {th }}$ uses and there was no statistical significant difference among the different uses $(\mathrm{P}>0.05)$.

\section{Group III (Continuous rotation motion):}

The mean deformation scores after the first three uses denoting no deformation, then the value is slightly higher after the $4^{\text {th }}$ use followed by $5^{\text {th }}$ and $6^{\text {th }}$ uses and there was no statistical significant difference among the different uses $(\mathrm{P}>0.05)$.

\section{II- Scanning electron microscopic (SEM) results: (Figure 2)}

Changes in the TF Adaptive instrument (SM2) (after $3^{\text {rd }}$ use, 4 th use and $6^{\text {th }}$ use) were shown in Figure (2).

Table (1): The mean values and standard deviation (SD) of deformation scores within each tested group after each use.

\begin{tabular}{|c|c|c|c|c|c|c|}
\hline \multirow{2}{*}{ Use } & \multicolumn{2}{|c|}{$\begin{array}{c}\text { Group I } \\
\text { (Adaptive motion) }\end{array}$} & \multicolumn{2}{|c|}{$\begin{array}{c}\text { Group II } \\
\text { (Reciprocating motion) }\end{array}$} & \multicolumn{2}{|c|}{$\begin{array}{c}\text { Group III } \\
\text { (Continuous rotation motion) }\end{array}$} \\
\hline & Mean & SD & Mean & SD & Mean & SD \\
\hline $\mathbf{1}^{\text {st }}$ use & 1.00 & 0.00 & 1.00 & 0.00 & 1.00 & 0.00 \\
\hline $2^{\text {nd }}$ use & 1.00 & 0.00 & 1.00 & 0.00 & 1.00 & 0.00 \\
\hline $3^{\text {rd use }}$ & 1.00 & 0.00 & 1.00 & 0.00 & 1.00 & 0.00 \\
\hline $4^{\text {th }}$ use & 1.20 & 0.42 & 1.10 & 0.32 & 1.20 & 0.42 \\
\hline $5^{\text {th }}$ use & 1.30 & 0.48 & 1.10 & 0.32 & 1.60 & 0.84 \\
\hline $6^{\text {th }}$ use & 1.30 & 0.48 & 1.10 & 0.32 & 1.60 & 0.84 \\
\hline$P$-value & \multicolumn{2}{|c|}{0.053} & \multicolumn{2}{|c|}{0.416} & \multicolumn{2}{|c|}{0.410} \\
\hline
\end{tabular}

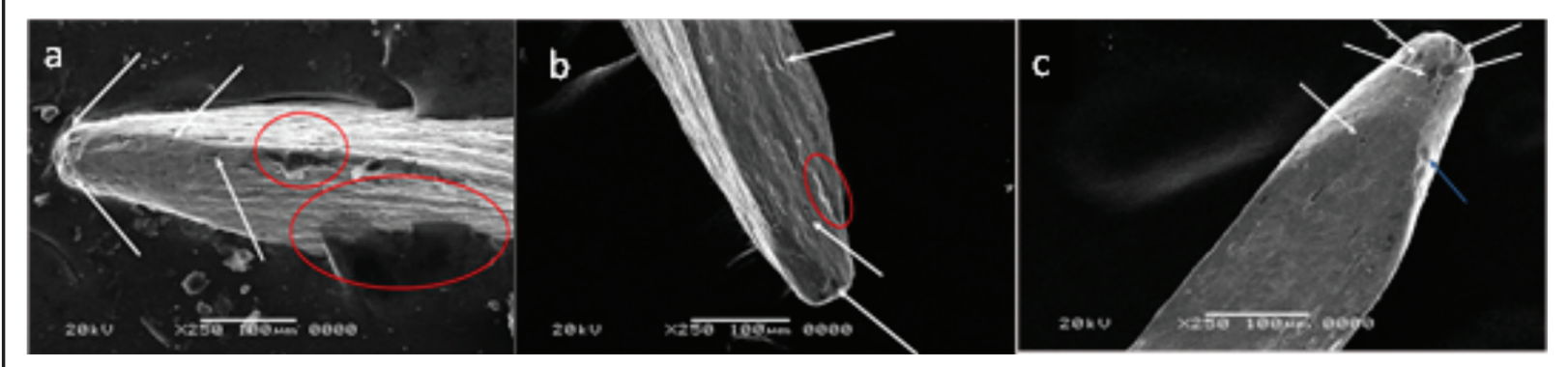

Figure (2): SEM images of TF Adaptive instruments after $6^{\text {th }}$ use and $2^{\text {nd }}$ sterilization cycle showing disruption of the cutting edge (loss of the regular continuous shape) (circle) and crater (pits in the cutting tip and surface) (arrows) (X 250). a) Adaptive motion; b) Reciprocating motion and c) Continuous rotation motion. 


\section{DISCUSSION}

Satisfactory biomechanical preparation can be achieved using nickel-titanium rotary instruments due to their super elasticity and greater flexibility however; the greatest problem of niti instruments is their sudden fracture ${ }^{(1)}$.

The results of the current study showed that, after the first, second and third uses, there was no statistical significant difference among the adaptive motion, reciprocating motion and continuous rotation motion in the mean deformation scores. This could be attributed to the design of TF instruments and their manufacturing process (twisting of NiTi alloy in the R-phase) instead of conventional grinding process, which produce machining defects on the surface of NiTi files and these defects cause microcrack formation, which in turn propagate during instrumentation and lead to instrument failure. In addition, the electropolishing procedure that removes surface roughnesses and increases resistance to intracanal stress ${ }^{(22)}$.

The results of the present study are in accordance with a recent study, which did not observe any deformation of TF files in the first three uses ${ }^{(24)}$. On the other hand, the results of the present study were inconsistent with previous study, which reported that, TF instruments showed deformation during the first use ${ }^{(25)}$. This could be attributed to the use of short radii of curvature ( 3 and $5 \mathrm{~mm}$ ) compared to $<40 \mathrm{~mm}$ that used in the present study.

After the fourth use, TFA instruments used with reciprocating motion had lower deformation scores than TFA instruments used with either adaptive motion or continuous rotation motion. However, there was no statistical significant difference among the tested groups in the mean deformation scores. This could be attributed to the reciprocating motion which subjected the files to stresses at lower magnitudes due to the shorter angular distance traversed by the instrument ${ }^{(26)}$. Also, reciprocating motion may allow better distribution of stresses than continuous rotation and adaptive motions, where it allows the release of reaction stresses built up in the material by reversing the rotational direction. Moreover, reciprocating motion prevents the taper lock phenomenon by unsymmetrical repeating of the clockwise and counterclockwise rotations ${ }^{(10)}$.

In corroboration with the results of present study, previous studies reported that, the reciprocating motion increases failure resistance and prolongs life span of the instruments ${ }^{(26,27)}$.

The comparable results between adaptive motion and continuous rotation motion could be explained by that, in the adaptive motion, the intracanal stresses were not high enough to induce reciprocating motion, therefore the adaptive motion acts as interrupted continuous rotation ${ }^{(22)}$. The results of the present study were consistent with another study which reported that, there was no significant difference in the instrument failure resistance between the adaptive motion and rotary motion ${ }^{(19)}$. On the contrary, a previous study showed that adaptive motion significantly increases the time to fracture TF instruments when compared with continuous rotation motion ${ }^{(28)}$. These discrepancies might be attributed to the use of $60^{\circ}$ degree angle of curvature compared to $15^{\circ}-35^{\circ}$ angle of curvature used in the present study.

After the fifth and sixth uses, the lowest mean deformation scores was recorded in TFA instruments used with reciprocating motion followed by TFA instruments used with adaptive motion while the highest mean deformation scores was recorded in TFA instruments used with continuous rotation motion. However, there was no statistical significant difference among the tested groups in the mean deformation scores. The results of mean deformation scores that recorded in the present study are supported by the results of deformation percentage, where TFA instruments used with reciprocating motion produced the lowest deformation percentage $(10 \%)$ followed by TFA instruments used with adaptive motion (30\%) while the highest deformation percentage was recorded in TFA instruments used with continuous rotation motion (40\%). 
The highest mean deformation scores and deformation percentage recorded with the continuous rotation motion could be explained by increased instrument experiences in tension/compression during rotation at the point of greatest curvature, which increase the cyclic fatigue and separation of endodontic files ${ }^{(29,30)}$. Moreover, it has been reported that, the continuous rotation motion is leading cause of NiTi instrument failure, with deformation, metal fatigue and subsequent breakage being potential problems associated with the use of 360 rotary instruments in curved canals ${ }^{(31)}$. The results of the present study are supported by a recent study which concluded that movement kinematics affects lifespan of TF files, where the reciprocal rotation extends lifespan of TF files ${ }^{(27)}$.

In the present study, the SEM evaluation of the TFA instrument used with adaptive motion, reciprocating motion or continuous rotation motion revealed that, the most prevalent defects were disruption of the cutting edge (straightening or loss of the regular continuous shape) and craters (pits in the cutting tip and surface). Disruption of the cutting edge was observed likely resulting from the torque applied to the shank of the file, which allow the stresses to be dissipated via the cutting edge ${ }^{(7)}$. These findings are in accordance with the results of previous study reported that as the number of canal usage increased chipping of the cutting edge was noted on TF instruments ${ }^{(32)}$.

In the current study, the prevalence of deformation in the form of pitting was observed. This could be related to the use of $2.6 \% \mathrm{NaOCl}$ irrigant concomitantly with the canal preparation. It has been concluded that, $\mathrm{NaOCl}$ was associated with deterioration of the surface of the instrument, as a result of a chemical reaction creating roughness and pitting ${ }^{(33)}$.

All the surface deformation was observed in the apical third of the instrument. This was possibly related to the torsional stresses that occurred in the apical part of the files during initial negotiation and canal enlargement. It has been reported that the beginning point of unwinding of instruments occurred mostly at or very close to the tip of the instrument ${ }^{(34)}$. Moreover, the tapering of the file increased toward the handle, making the bulk of the file much stronger than its tip ${ }^{(35)}$.

The combination of heat treatment and twisting process leads the TFA instruments to present a clinical behavior different from the majority of grounded NiTi rotary instruments ${ }^{(17)}$.

\section{CONCLUSION}

Within the limitations of the present study, the following could be concluded:

1. The innovated adaptive motion did not result in lower deformation of TF Adaptive files.

2. Reciprocating motion produced less deformation in TF Adaptive files than did adaptive motion or continuous rotation motion, after preparing six root canals.

3. Cumulative effect of several factors including repeated steam autoclaving, number of uses and irrigating solutions did not affect the deformation of TF Adaptive files.

\section{REFERENCES}

1. You SY, Bae KS, Baek SH, Kum KY, Shon WJ, Lee W. Lifespan of one Nickel-Titanium rotary file with reciprocating motion in curved root canals. J Endod 2010; 36:1991-4.

2. Burklein S, Hinschitza K, Dammaschke T, Schafer E. Shaping ability and cleaning effectiveness of two single file systems in severely curved root canals of extracted teeth: Reciproc and WaveOne versus Mtwo and ProTaper. Int Endod J 2012; 45: 449-61.

3. Glosson CR, Haller RH, Dove SB, Del Rio CE. A comparison of root canal preparations using NiTi hand, NiTi Engine driven and K-Flex Endodontic instruments. J Endod 1995; 21: 146-51.

4. Tygesen YA, Steinman HR, Ciavarro C. Comparison of distortion and separation utilizing Profile and Pow-R nickel titanium rotary files. J Endod 2001; 27: 762-4.

5. Yared GM, Bou Dager FE, Machtou P. Failure of ProFile instruments used with high andlow torque motors. Int Endod J 2001; 34: 471-5. 
6. Yared G, Kulkarni GK, Ghossayan F. An invitro study of the torsional properties of new and used K3 instruments. Int Endod J 2003; 36: 764-69.

7. Pruett JP, Clement DJ, Carnes DL Jr. Cyclic fatigue testing of nickel-titanium endodontic instruments. J Endod 1997; 23: 77-85.

8. Zupanc J, Vahdat-Pajouh N, Sch€afer E. New thermomechanically treated NiTi alloys - a review. Int Endod J 2018; 51:1088-103.

9. Parashos P and Messer HH. Rotary NiTi instrument fracture and its consequences. J Endod 2006; 32:1031-43.

10. De-Deus G, Moreira E, Lopes H, Elias C. Extended cyclic fatigue life of F2 ProTaper instruments used in reciprocating movement. Int Endod J 2010; 43:1063-8.

11. Varela-Patino P, Ibanez-Parraga A, Rivas-Mundina B, Canta-tore G, Otero XL, Martin-Biedma B. Alternating versus continuous rotation: a comparative study of the effect on instrument life. J Endod 2010; 36:157-9.

12. Wan J, Rasimick BJ, Musikant BL, Deutsch AS. A comparison of cyclic fatigue resistance in reciprocating and rotary nickel-titanium instruments. Aust Endod J 2011; 37: 122-7.

13. Saber SED and Abu El Sadat SM. Effect of altering the reciprocation range on the fatigue life and the shaping ability of WaveOne nickel-titanium instruments. J Endod 2013; 39: 685-8.

14. Fidler. A Kinematics of 2 reciprocating endodontic motors: the difference between actual and set values. J Endod 2014; 40: 990-4.

15. Bürklein S and Schäfer E. Apically extruded debris with reciprocating single-file and full sequence rotary instrumentation systems. J Endod 2012; 38: 850-2.

16. Gambarini G, Sudani DAL, Di Carlo S, Pompa G, Pacifici A, Pacifici L, Testarelli L. Incidence and intensivity of postoperative pain and periapical inflammation after endodontic treatment with two different instrumentation techniques. Europ. J. Inflam 2012; 10:99-103.

17. TF Adaptive. Available: http://axis.sybronendo.com/tf adaptive confidence\# tab2.Accessed June 4, 2015.

18. Ozyurek T, Keskin C, Demiryurek EO. Energy consumption of Twisted File instrument used with rotary or reciprocating adaptive motion. Eur J Gen Dent 2016; 5: 65-8.

19. Keskin B, Ozyurek T, Furuncuoğlu F, İnan U. The effects of adaptive motion on cyclic fatigue resistance of twisted files. J Dent App 2016; 3: 337-9.

20. Schneider SW. Acomparison of canal preparation in straight and curved root canals. Oral Surg Oral Med Oral Path 1971; 32:271-5.

21. Estrela C, Bueno MR, Sousa-Neto MD, Pecora JD. Method for determination of root curvature radius using cone -beam computed tomography images. Braz Dent J 2008; 19:114-8.
22. Gambarini G and Glassman G. TF adaptive: a novel approach to nickel-titanium instrumentation. Oral Health 2013; 7:22-30

23. Gambarini G, Rubini AG, Al Sudani D Gergi R, Culla A, De Angelis F, et al. Influence of different angles of reciprocation on the cyclic fatigue of nickel-titanium endodontic instruments. J Endod 2012; 38: 1408-11.

24. Caballero H, Rivera F, Salas H. Scanning electron microscopy of superficial defects in Twisted files and Reciproc nickel titanium files after use in extracted molars. Int Endod J 2015; 48: 229-35.

25. Gambarini G, Piasecki L, Di Nardo D, Miccoli G, Di Giorgio G, Carneiro E, et al. Incidence of Deformation and Fracture of Twisted File Adaptive Instruments after Repeated Clinical Use. J Oral Maxillofac Res 2016; $7:$ :5

26. Pedulla E, Grande NM, Plotino G, Gambarini G, Rapisarda E Influence of continuous or reciprocating motion on cyclic fatigue resistance of 4 different nickel-titanium rotary instruments. J Endod 2013; 39: 258 -61.

27. Karova E, Pirinska ST, Stoeva I. Lifespan analysis of twisted file rotary NiTi instruments used in different modes of rotation. Wulfenia J 2016; 23:214-21

28. Gambarini $G$ and Glassman G. In vitro analysis of efficiency and safety of a new motion for endodontic instrumentation: TF Adaptive. Roots 2013; 3: 12-15.

29. Melo MCC, Bahia MGA, Buono VTL (2002) Fatigue resistance of engine-driven rotary nickel-titanium endodontic instruments. J Endod 28; 765-9.

30. Pessoa OF, Silva JM, Gavini G.Cyclic fatigue resistance of rotary NiTi instruments after simulated clinical use in curved root canals. Braz Dent J 2013; 24: 117-20.

31. Dederich DN, Zakariasen KL. The effects of cyclical axial motion on rotary endodontic instrument fatigue. Oral Surg Oral Med Oral Path 1986; 61: 192-6.

32. Kottoor J, Velmurugan N, Gopikrishna V, Krithikadatta J. Effects of multiple root canal usage on the surface topography and fracture of two different Ni-Ti rotary file systems. Indian J Dent Res 2013; 24:42-7.

33. Fayyad DM and Mahran AH. Atomic force microscopic evaluation of nanostructure alterations of rotary NiTi instruments after immersion in irrigating solutions. Int Endod J 2014; 47: 567-73.

34. Parashos P, Gordon I, Messer HH. Factors influencing defects of rotary nickel-titanium endodontic instruments after clinical use. J Endod 2004; 30:722-5.

35. Sattapan B, Nervo GJ, Palamara JE, Messer HH. Defects in rotary nickel-titanium files after clinical use. J Endod 2000; 26:161-5. 